\title{
Methods and Evaluation of Soybean Genotypes for Resistance to Colletotrichum truncatum
}

Hui-Ching Yang, Department of Natural Resources and Environmental Sciences, and Glen L. Hartman, United States Department of Agriculture-Agricultural Research Service and Department of Crop Sciences, University of Illinois, Urbana 61801

\begin{abstract}
Yang, H.-C., and Hartman, G. L. 2015. Methods and evaluation of soybean genotypes for resistance to Colletotrichum truncatum. Plant Dis. 99:143-148.

Anthracnose of soybean (Glycine max) occurs throughout the soybean production areas of the world. There is little information on evaluating inoculation techniques or evaluating soybean germplasm for resistance. The objectives of this study were to develop a reliable inoculation technique for evaluating soybean for resistance to Colletotrichum truncatum and to evaluate soybean genotypes for resistance. Inoculated plants incubated in a dew chamber for 48 or $72 \mathrm{~h}$ had higher $(P=0.05)$ area under disease progress curve (AUDPC) values than when incubated for $24 \mathrm{~h}$. Three experiments evaluated soybean genotypes for resistance to $C$. truncatum. In the first experiment using 15 soybean genotypes, 'Mandarin' had lower $(P=0.05)$ AUDPC values than all the other genotypes except for 'Mandarin 507', 'Mandarin (Ottawa)', and

darin 507 had lower $(P=0.05)$ AUDPC values compared with all other soybean genotypes except 'Early White Eyebrow', 'Mandarin Yowa', Boone, and 'Manchuria'. In the third experiment, Mandarin 507 had lower $(P=0.05)$ AUDPC values compared with 23 other soybean genotypes except 'Spry', Mandarin, and 'Iroquois'. Plants of Mandarin 507 and 'Williams 82' were inoculated at the vegetative and reproductive growth stages; Mandarin 507 had lower $(P=0.05)$ AUDPC values compared with Williams 82 for both growth stages evaluated, and Mandarin 507 had less $(P=0.05)$ pod area covered by lesions compared with the pods of Williams 82. This study provided a descriptive method to inoculate soybean plants with $C$. truncatum and identified soybean genotypes with resistance to anthracnose.
\end{abstract} 'Boone'. In the second experiment using 28 soybean genotypes, Man-
Anthracnose of soybean (Glycine max (L.) Merr.) occurs throughout the soybean production areas of the world (16). Soybean plants can be infected at any stage of development. Symptoms include irregularly shaped brown blotches and cankering on stems, petioles, and pods; necrosis of laminar veins; rolling leaves; and premature defoliation. Infected seed often become discolored and may die during germination (9). The disease is more prevalent under humid and warm conditions. Yield reduction from anthracnose has been reported in Asia, Europe, and South and North America $(3,16,28,29)$. Anthracnose was reported to cause 16 to $26 \%$ seed yield loss in the southern area of the United States (3). From 2003 to 2005, anthracnose was among the top 10 most important soybean diseases in terms of monetary losses averaged over 15 southern states (28). Disease management includes fungicide application, crop rotation with nonhosts, and planting pathogenfree seed (16). Although no commercial cultivars are advertised to have resistance to anthracnose, sources of resistance have been reported $(5,14,18-20)$.

Colletotrichum truncatum (Schwein.) Andrus \& W.D. Moore, one species commonly reported to cause anthracnose, survives in

Corresponding author: G. L. Hartman, E-mail: ghartman@illinois.edu

Trade and manufacturers' names are necessary to report factually on available data; however, the United States Department of Agriculture (USDA) neither guarantees nor warrants the standard of the product, and the use of the name by USDA implies no approval of the product to the exclusion of others that may also be suitable.

* The $e$-Xtra logo stands for "electronic extra" and indicates that three supplementary figures are available online.

Accepted for publication 24 July 2014.

http://dx.doi.org/10.1094/PDIS-03-14-0228-RE

This article is in the public domain and not copyrightable. It may be freely reprinted with customary crediting of the source. The American Phytopathological Society, 2015. soybean debris and is seedborne $(16,24)$. The disease cycle and infection process include primary infection on plants from overwintered spores or mycelia on diseased plant tissues, germination of spores, development of appressoria and infection pegs, penetration and hyphal colonization of host tissue, and production of acervuli and spores. During the growing season, infection continues as acervuli produce spores that are rain splashed and land, germinate, and penetrate plant tissues $(1,21)$. To study anthracnose of soybean, plants have been inoculated with conidial and mycelial suspensions with different Colletotrichum spp. $(4,11,14,20,21,23)$. Conditions to promote anthracnose development on soybean seedlings showed that longer incubation times in a mist chamber produced more severe symptoms, with younger plants having more stem tip necrosis than older plants (20).

There are few studies that have evaluated anthracnose resistance in soybean. Several studies reported on the evaluation of 414 soybean germplasm accessions to $C$. truncatum (18-20). These studies found no immune genotypes; however, 10 genotypes in maturity groups (MGs) 00 to IV ('Bavendar Sp. A', 'Boone', 'Early White Eyebrow', 'Gibson', 'Manchuria', 'Mandarin', 'Mandarin [Ottawa]', 'Waseda', 'Wea', and 'Willomi'), plant introduction (PI) 96860 in MG VI, and 'Tarheel Black' in MG VII were classified as resistant. In another study (14), 'A. K. (Kansas)', Boone, 'Corsoy 79', and 'Williams 82' soybean were used to investigate the pathogenicity of sclerotia- and nonsclerotia-forming isolates of $C$. truncatum on seedling roots; all were reported susceptible to root infection by $C$. truncatum. In addition, 48 commercial soybean cultivars in Brazil were evaluated for the resistance to $C$. truncatum under greenhouse conditions. Although no cultivar was immune, 45 were classified as resistant or intermediate, and only 3 cultivars were susceptible (5). Breeding efforts to produce anthracnose-resistant soybean cultivars are lacking despite the potential for yield losses due to this disease. In addition, there is a lack of knowledge about soybean resistance in different tissues (from roots to seed) and whether any described resistance would be effective against the several species of Colletotrichum that cause anthracnose.

The soybean genotype Mandarin was among the soybean genotypes reported to have resistance to anthracnose $(18,19)$, although 
the PI number was not provided in these publications. In the soybean germplasm collection (26), along with Mandarin (listed as PI 548378) there also are 'Mandarin Yowa' (PI 189890), 'Mandarin A' (PI 438363), and 'Mandarin 507' (PI 548380) that, to our knowledge, have not been evaluated for resistance to anthracnose. The $C$. truncatum isolates used in previous studies to evaluate soybean accessions for anthracnose resistance have not been curated and are not available for use today. However, the soybean genotypes that were previously reported can be evaluated with newly collected isolates.

The genetic base of North American soybean cultivars is from a narrow range of ancestral lines. Fourteen soybean introductions were reported to constitute about $70 \%$ of the genes in North American public cultivars released from 1971 to $1981(6,9)$. A set of 35 soybean ancestors that contributed to $>95 \%$ of the genes found in North American cultivars were released between 1947 and 1988 (10). These ancestral lines have been evaluated for resistance to soybean sudden death syndrome (22) and for four soybean viruses (27) but not for resistance to anthracnose.

The objectives of this study were to (i) develop a reliable inoculation technique to evaluate soybean genotypes for resistance to anthracnose and (ii) use this technique to evaluate soybean genotypes previously reported to be resistant to anthracnose, a set of soybean ancestral lines, and a set of public soybean cultivars.

\section{Materials and Methods}

Fungal isolate. An isolate of C. truncatum (IL15B) was obtained from soybean petioles and stems collected in Urbana, IL in 2009. This isolate was selected as the most aggressive isolate in a preliminary detached-leaf assay for screening the pathogenicity of 84 Colletotrichum isolates collected in the United States in 2009 (30). The isolate was identified as $C$. truncatum according to its morphological characteristics and DNA sequence analysis (30). The isolate was maintained on potato dextrose agar (PDA; BD Difco, Sparks, MD) at the National Soybean Research Center in the Laboratory for Soybean Diseases Research at the University of Illinois (www.soydiseases.illinois.edu). The isolate was transferred periodically as needed and incubated under $12 \mathrm{~h}$ of alternating cool-white fluorescent light $\left(45 \mu \mathrm{mol} \mathrm{m} \mathrm{m}^{-2} \mathrm{~s}^{-1}\right)$ and darkness at $24 \pm$ $1^{\circ} \mathrm{C}$.

Inoculum preparation. Six 4-mm-diameter mycelial disks from an actively growing culture of isolate IL15B on PDA were added to $50 \mathrm{ml}$ of autoclaved and cooled potato dextrose broth (PDB; BD Difco) in 250-ml flasks. The flasks were secured to a shaker (LabLine Instrument, Melrose Park, IL) at $100 \mathrm{rpm}$ and incubated for 5 days at room temperature $\left(24 \pm 1^{\circ} \mathrm{C}\right)$. The mycelial suspension was transferred to 50-ml tubes (Corning Inc., Corning, NY) and centrifuged at 2,500 rpm for $20 \mathrm{~min}$ (Centrifuge 5810; Eppendorf, Hauppauge, NY). The pellet was collected, squeezed to minimize liquid content, then weighed. The pellet was resuspended in distilled water, fragmented with a blender (Model 31BL92; Waring Laboratory, Torrington, CT) at low speed for $30 \mathrm{~s}$, stopped for $30 \mathrm{~s}$, and ground for another $30 \mathrm{~s}$. In preliminary tests, final concentrations of mycelial suspensions of 20 to $100 \mathrm{mg} / \mathrm{ml}$ in distilled water caused severe symptoms on Williams 82 plants, with no significant differences in anthracnose severity among the suspensions (data not shown).

Incubation chambers. To keep plants moist after inoculation, space limitations necessitated the use of two kinds of chambers (commercial dew chambers and homemade moist chambers). Two dew chambers (Percival Scientific Inc., Perry, IA) with the lights switched off were set at a wall temperature of $19^{\circ} \mathrm{C}$ and a water temperature of $32^{\circ} \mathrm{C}$. The temperature recorded was $24 \pm 2^{\circ} \mathrm{C}$, with a relative humidity of over $80 \%$. The moist chambers were constructed using plastic crates (interior size: 57 by 37 by $41 \mathrm{~cm}$ ), covered and sealed with insulated foil bubble wrap. A stainless steel test-tube rack ( 34 by 18 by $10 \mathrm{~cm}$ ) was placed inside each crate to support one flat ( 52 by 26 by $6 \mathrm{~cm}$ ) with plants in multiple pot inserts. Water (5 liters) was added to the bottom of each crate and the inside walls were sprayed with water using a hand-held sprayer (Do it Best Corp., Fort Wayne, IN) before setting plants inside. The moist chambers were kept in a growth chamber room at $28 \pm 2{ }^{\circ} \mathrm{C}$ with a relative humidity greater than $90 \%$.

Effect of inoculum type and incubation period on anthracnose severity. Six treatments, including two inoculum types (mycelia and conidia) and three dew periods $(24,48$, and $72 \mathrm{~h}$ ), were arranged as a factorial in a completely randomized design with three replications. Each experimental unit consisted of three plants.

Seed of Williams 82 were planted in three pots $(11 \mathrm{~cm}$ in diameter) and thinned to three plants per pot. The plants were grown in a growth chamber (Percival Scientific Inc.) with $12 \mathrm{~h}$ of alternating light $\left(350 \mu \mathrm{mol} \mathrm{m} \mathrm{m}^{-2} \mathrm{~s}^{-1}\right)$ and darkness at $25^{\circ} \mathrm{C}$ and, when 12 days old or at growth stage V1 (8), they were moved to a dew chamber for inoculation.

Mycelial inoculum at a concentration of $40 \mathrm{mg} / \mathrm{ml}$ was prepared as previously described. Conidial inoculum was prepared according to Manandhar et al. (20), with slight modifications. Briefly, IL15B cultures were grown on sodium chloride-yeast extract agar (SYA) plates (17) with alternating $12 \mathrm{~h}$ of light $\left(45 \mu \mathrm{mol} \mathrm{m} \mathrm{m}^{-2} \mathrm{~s}^{-1}\right)$ and dark condition at $24 \pm 1^{\circ} \mathrm{C}$ for 3 to 4 weeks to facilitate spore production. Conidia were harvested from the plates by adding 20 $\mathrm{ml}$ of sterile distilled water per plate. The surface was brushed using a plastic disposable loop (Nunc, Thermo Fisher Scientific, Rochester, NY). The conidia in suspension were calculated by a hemacytometer (Reichert Bright Line, Buffalo, NY) and diluted to a final concentration of $3 \times 10^{6}$ conidia $/ \mathrm{ml}$ in distilled water.

Plants were atomized with the mycelial or conidial suspension until run-off. Plants were incubated in a dew chamber at $25^{\circ} \mathrm{C}$ in the dark for 24,48 , and $72 \mathrm{~h}$. Plants were removed and placed back in the growth chamber. Disease severity was rated on a whole plant basis daily from 4 to 10 days postinoculation (DPI).

Disease severity was based on visual assessment of inoculated plants using a pretransformed rating scale (15) from 0 to 5 , where $0=$ no visible symptoms, $1=1$ to $10 \%$ of the plant affected (primarily leaf vein necrosis), $2=11$ to $35 \%$ of the plant affected (primarily leaf and some petiole necrosis), $3=36$ to $65 \%$ of the plant affected (primarily leaf, petiole, and some stem necrosis), $4=$ 66 to $90 \%$ of the plant affected (extensive leaf, petiole, and stem necrosis), and $5=91$ to $100 \%$ of the plant affected (severe necrosis on all plant parts to plant death).

Effect of plant age on disease severity. Plants of five different growth stages (VC, V1, V2 to V3, R3 to R4, and R4 to R5) were arranged in a completely randomized design with four replications. Each experimental unit consisted of three plants per pot.

Seed of Williams 82 were planted weekly for 5 weeks in pots $(11 \mathrm{~cm}$ in diameter) and thinned to three plants per pot. Plants were grown in a growth chamber (Percival Scientific Inc.) with $12 \mathrm{~h}$ of alternating light $\left(350 \mu \mathrm{mol} \mathrm{m} \mathrm{m}^{-2} \mathrm{~s}^{-1}\right)$ and darkness at $25^{\circ} \mathrm{C}$. When plants from the first sowing date developed to growth stages R4 to R5 (43-day-old plants), plants for all the treatments were inoculated with a mycelial suspension of isolate IL15B, as previously described, by atomizing plants until run-off. Inoculated plants were placed in moist chambers in the dark at $28 \pm 2^{\circ} \mathrm{C}$ and, after $72 \mathrm{~h}$, transferred back to the growth chamber. Disease severity, based on the previously described visual assessment, was rated at 4, 5, 6, and 9 DPI. The experiment was repeated.

Evaluation of three sets of soybean genotypes for anthracnose resistance. The first set included 15 soybean genotypes consisting of 10 genotypes reported to be resistant $(18,19)$, plus Mandarin Yowa, Mandarin A, Mandarin 507, 'T269H' (random selection from the collection with an unknown reaction to anthracnose), and the susceptible check Williams 82 . The second set included 28 soybean genotypes consisting of all the genotypes in the first set (excluding T269H), plus 12 soybean ancestral lines (9), Hartwig, and Kingwa. The third set included 25 public soybean cultivars and Williams 82 as the susceptible check, and Mandarin 507 and Mandarin as the resistant checks.

For all three experiments, seed were sown in a soil-less medium, Sunshine Mix LC1 (Sun Gro Horticulture Inc.), in 18 or 36 multicelled flats ( 52 by 26 by $6 \mathrm{~cm}$ ). The design for each experiment 
was a randomized complete block, with soybean genotypes randomized within each block. Each flat was a block (replication), with three blocks per each experiment. In each cell, two to three seeds were sown and thinned, if needed, to two plants per cell (experimental unit) for the first experiment and one plant per cell for experiments two and three. Plants were grown in a growth chamber (Percival Scientific Inc.) at $25^{\circ} \mathrm{C}$ under $14 \mathrm{~h}$ of light $\left(350 \mu \mathrm{mol} \mathrm{m} \mathrm{m}^{-2}\right.$ $\mathrm{s}^{-1}$ ) per day for $21 \pm 3$ days, corresponding to a growth stage of V2 to V3 before inoculation. Plants were inoculated with a mycelial suspension of isolate IL15B as previously described. After inoculation, plants were placed in moist chambers at $28 \pm 2{ }^{\circ} \mathrm{C}$ in the dark. After $48 \mathrm{~h}$ of incubation, plants were moved back to the growth chamber. Anthracnose severity, based on the previously described visual assessment, was rated daily from 3 to 8 DPI and 10 DPI for the first experiment, daily from 3 to 7 DPI for the second experiment, and daily from 3 to 9 DPI for the third experiment. All three experiments were repeated with different randomizations within blocks.

Effect of plant age on a resistant and a susceptible genotype. Seed of two soybean genotypes, Mandarin 507 (resistant) and Williams 82 (susceptible), were sown in plastic pots $(13 \mathrm{~cm}$ in diameter) and thinned to three plants per pot in a growth chamber (Percival Scientific Inc.) with $12 \mathrm{~h}$ of alternating light $\left(350 \mu \mathrm{mol} \mathrm{m} \mathrm{m}^{-2} \mathrm{~s}^{-1}\right)$ and darkness at $25^{\circ} \mathrm{C}$. To obtain plants at two different growth stages, seed of both genotypes were planted 35 and 40 days after the initial planting for trial 1 and trial 2, respectively. For each trial, 36 plants ( 3 plants per pot, three replications, two genotypes, and two growth stages) were inoculated with isolate IL15B when plants were in the vegetative growth stage (V1 to V2, or 13 and 19 days after sowing for trial 1 and trial 2, respectively) and in the reproductive growth stage (R4 up to R6, or 47 and 50 days after sowing for trial 1 and trial 2, respectively). Disease severity, based on the previously described visual assessment, was rated daily from 3 to 8 DPI. In trial 2, plants that were inoculated in the reproductive growth stage were also rated for anthracnose severity on pods. In total, 57 and 68 pods of Mandarin 507 and Williams 82, respectively, were evaluated at $20 \mathrm{DPI}$.

Data analysis. Midpoint percentages of the ratings were used to calculate area under the disease progress curve (AUDPC) (25), which was used as the variable in all experiments. In addition, pods were evaluated in the experiment where one resistant and one susceptible genotype were compared at their vegetative and reproductive growth stages. The pod evaluation was rated once, and the variable used for analysis to compare the soybean genotypes was

Table 1. Restricted or maximum likelihood analysis of experiments to evaluate inoculation techniques and to evaluate soybean genotypes for resistance to Colletotrichum truncatum (anthracnose) based on the area under disease progress curve values

\begin{tabular}{llrc}
\hline Experiment & \multicolumn{1}{c}{ Source } & df & \multicolumn{1}{c}{$\boldsymbol{P}>\mathbf{F}$} \\
\hline Inoculum type and incubation $^{\mathrm{u}}$ & Type $\times$ time & 5 & $<0.0001$ \\
Plant age at inoculation $^{\mathrm{v}}$ & Growth stages & 4 & $<0.0001$ \\
Previously reported sources $^{\mathrm{w}}$ & Soybean genotype & 14 & $<0.0001$ \\
Ancestral set, previous sources $^{\mathrm{x}}$ & Soybean genotype & 27 & $<0.0001$ \\
Public cultivars $^{\mathrm{y}}$ & Soybean genotype & 27 & $<0.0001$ \\
Resistant versus susceptible $^{\mathrm{z}}$ & Growth stages & 3 & $<0.0001$ \\
\hline
\end{tabular}

u Based on six treatments, two inoculum types (mycelia and conidia), three dew periods $(24,48$, and $72 \mathrm{~h})$, and three replications using three plants per experimental unit.

${ }^{v}$ Based on five growth stage treatments (VC, V1, V2 to V3, R3 to R4, and R4 to R5) and eight replications (combined two trials of four replications each) using three plants per experimental unit.

${ }^{\text {w }}$ Based on 15 soybean genotypes and six replications (combined two trials of three replications each) using two plants per experimental unit.

${ }^{x}$ Based on 28 soybean genotypes and six replications (combined two trials of three replications each) using one plant per experimental unit.

y Based on 28 soybean genotypes and six replications (combined two trials of three replications each) using two plants per experimental unit.

${ }^{\mathrm{z}}$ Based on four treatments, two plant growth stages, two soybean genotypes, and six replications (combined two trials of three replications each) using three plants per experimental unit. the pretransformed rating scale that was detransformed to percent for presentation. The homogeneity of variance for the AUDPC values among repeated experiments was tested using Bartlett's test (JMP, version 11; SAS Institute Inc., Cary, NC). Restricted or residual maximum likelihood (REML) analysis of the AUDPC values was performed with JMP with replications as random effects and treatments as fixed effects. When significant differences were indicated in the REML analysis, least square means were compared using least significant difference at $P=0.05$.

\section{Results}

Effect of inoculum type and incubation period on anthracnose severity. There were significant $(P<0.0001)$ differences among the treatments for AUDPC values (Table 1), with the highest AUDPC value for plants inoculated with a mycelial suspension and incubated for 48 or $72 \mathrm{~h}$ and for plants inoculated with a conidial suspension and incubated for $72 \mathrm{~h}$ (Table 2). The AUDPC values between the 24-h incubation period with the mycelial inoculum and the 48-h incubation period with the conidial inoculum were not significantly different. The treatment with the lowest AUDPC value was conidial inoculum with an incubation period of $24 \mathrm{~h}$.

Effect of plant age on disease severity. The homogeneity of variance for the AUDPC values between the two trials was not significant $(P<0.3859)$ based on the Bartlett's test and the data were combined for analysis and presentation. There were significant $(P<0.0001)$ differences among the growth stages for AUDPC values (Table 1). The AUDPC values for plants inoculated at vegetative growth stages were greater than values of plants inoculated at reproductive stages (Table 3 ). Plants inoculated at early vegetative growth stages had leaf necrosis and lesions on petioles and stems, and were defoliated by 4 DPI. Plants inoculated at the growth stage $\mathrm{VC}$ died 6 DPI. The majority of plants inoculated at V1 or V2 to V3 died at 9 DPI. Plants inoculated at R3 to R4 or R4 to R5 did not develop stem lesions until 6 DPI, although pod lesions were observed as brown, irregular-shaped blotches beginning at 4 DPI.

Evaluation of three sets of soybean genotypes for anthracnose resistance. The test of equal variances for the AUDPC values

Table 2. Area under disease progress curve (AUDPC) values based on daily visual severity rating from 4 to 10 days after inoculation for soybean Williams 82 inoculated with a mycelial or a conidial suspension of Colletotrichum truncatum and incubated in the dark at three different incubation periods

\begin{tabular}{lcl}
\hline Inoculum type $^{\mathbf{y}}$ & Incubation period (h) & AUDPC $^{\mathbf{z}}$ \\
\hline Mycelial & 72 & $353.4 \mathrm{~A}$ \\
Mycelial & 48 & $303.0 \mathrm{AB}$ \\
Conidial & 72 & $266.3 \mathrm{~B}$ \\
Mycelial & 24 & $151.8 \mathrm{C}$ \\
Conidial & 48 & $138.0 \mathrm{C}$ \\
Conidial & 24 & $11.0 \mathrm{D}$ \\
\hline
\end{tabular}

y Mycelial suspension $=40 \mathrm{mg} / \mathrm{ml}$ and conidial suspension $=3 \times 10^{6}$ conidia per $\mathrm{ml}$.

${ }^{\mathrm{z}}$ Means not connected by the same letter are significantly $(P=0.05)$ different by least significant difference.

Table 3. Area under disease progress curve (AUDPC) values based on daily visual severity rating at $4,5,6$, and 9 days after inoculation of soybean Williams 82 inoculated at five different growth stages with a mycelial suspension of Colletotrichum truncatum

\begin{tabular}{lcl}
\hline Growth stage $^{\mathbf{y}}$ & Plant age at inoculation (days) & AUDPCz $^{\mathbf{z}}$ \\
\hline VC & 8 & $372.8 \mathrm{~A}$ \\
V2 to V3 & 23 & $335.0 \mathrm{AB}$ \\
V1 & 14 & $309.2 \mathrm{~B}$ \\
R3 to R4 & 36 & $148.6 \mathrm{C}$ \\
R4 to R5 & 43 & $144.8 \mathrm{C}$ \\
\hline
\end{tabular}

${ }^{\mathrm{y}} \mathrm{V}=$ vegetative growth stages and $\mathrm{R}=$ reproductive growth stages (8).

${ }^{\mathrm{z}}$ Means not connected by the same letter are significantly $(P=0.05)$ different by least significant difference. 
among the three experiments was not significant $(P<0.861$, 0.2729 , and 0.244). Therefore, the data were combined for analysis and presentation. In all three experiments, AUDPC values were significantly different for soybean genotypes (Table 1).

In the first experiment, Mandarin had lower AUDPC values than all the other genotypes except for Mandarin 507, Mandarin (Ottawa), and Boone (Table 4). Early White Eyebrow, Mandarin A, and Mandarin Yowa had AUDPC values higher than Mandarin but lower than Williams 82.

In the second experiment, Mandarin 507 had lower AUDPC values compared with all other genotypes except Early White Eyebrow, Mandarin Yowa, Boone, and Manchuria (Table 5). Two genotypes, 'A. K. Harrow' and Kingwa, had higher AUDPC values than Williams 82. Of the genotypes classified as "ancestors", no genotypes differed in AUDPC from Williams 82 except A. K. Harrow, which had a higher value.

In the third experiment, Mandarin 507, 'Spry', Mandarin, and 'Iroquois' had lower AUDPC values than the 24 other genotypes tested (Table 6). Only seven genotypes had lower AUDPC values than Williams 82. This included two breeding lines (LN92-7369 and LN97-15076), three named cultivars ('Macon', Iroquois, and Spry), and the two resistant checks (Mandarin and Mandarin 507).

Effect of plant age on a resistant and a susceptible genotype. There were significant $(P<0.0001)$ differences between the soybean genotypes Mandarin 507 and Williams 82 in AUDPC at each of the growth stages and the severity of anthracnose on pods (Table 1). The highest AUDPC value occurred on Williams 82 plants at V1 to V2, which differed $(P=0.05)$ from all other treatments. The lowest AUDPC value occurred on Mandarin 507 at R4 to R6, which differed $(P=0.05)$ from all other treatments (Table 7$)$. In trial 2, percentage of pods covered with lesions was lower in Mandarin 507 (3.8\%) than in Williams 82 (39.5\%) (Fig. 1).

\section{Discussion}

The objectives of this study were fulfilled because a reliable inoculation technique was developed to evaluate soybean genotypes

Table 4. Area under disease progress curve (AUDPC) for soybean genotypes inoculated with Colletotrichum truncatum with their origin, plant introduction (PI) number, and maturity group (MG)

\begin{tabular}{|c|c|c|c|c|}
\hline Genotypes & Origin & PI & MG & $\mathbf{A U D P C}^{\mathbf{z}}$ \\
\hline Williams 82 & United States & 518671 & III & $335.6 \mathrm{~A}$ \\
\hline Willomi & Japan & 548425 & III & $312.5 \mathrm{AB}$ \\
\hline Waseda & Japan & 548423 & II & $299.3 \mathrm{AB}$ \\
\hline $\mathrm{T} 269 \mathrm{H}$ & United States & 548246 & III & $282.9 \mathrm{~A}-\mathrm{C}$ \\
\hline Wea & China & 548424 & II & $277.1 \mathrm{~A}-\mathrm{D}$ \\
\hline Manchuria & China & 548375 & I & $269.9 \mathrm{~A}-\mathrm{D}$ \\
\hline Gibson & United States & 548330 & IV & $249.2 \mathrm{~A}-\mathrm{D}$ \\
\hline Bavendar Sp. A & United States & 548304 & III & $239.0 \mathrm{~A}-\mathrm{D}$ \\
\hline Mandarin Yowa & France & 189890 & I & 234.4 B-D \\
\hline Mandarin A & Canada & 438363 & I & 216.5 B-E \\
\hline Early White Eyebrow & China & 548320 & 0 & 213.7 B-E \\
\hline Boone & China & 548309 & IV & $185.5 \mathrm{C}-\mathrm{F}$ \\
\hline Mandarin (Ottawa) & China & 548379 & 0 & 179.2 D-F \\
\hline Mandarin 507 & China & 548380 & I & $116.1 \mathrm{EF}$ \\
\hline Mandarin & China & 548378 & I & $88.1 \mathrm{~F}$ \\
\hline
\end{tabular}

${ }^{\mathrm{z}}$ Means not connected by the same letter are significantly $(P=0.05)$ different by least significant difference.

Table 5. Area under disease progress curve (AUDPC) for soybean genotypes inoculated with Colletotrichum truncatum with their reported use as ancestors to modern day public soybean cultivars released between 1947 to 1988, their origins, plant introductions number (PI), and maturity group (MG)

\begin{tabular}{|c|c|c|c|c|c|}
\hline Genotype & Ancestor $^{\mathrm{y}}$ & Origin & PI & MG & $\mathbf{A U D P C}^{\mathbf{z}}$ \\
\hline A. K. Harrow & Yes & China & 548298 & III & $268.5 \mathrm{~A}$ \\
\hline Kingwa & No & China & 548359 & IV & $250.1 \mathrm{AB}$ \\
\hline Arksoy & Yes & Korea & 548438 & VI & $243.3 \mathrm{~A}-\mathrm{C}$ \\
\hline S-100 & Yes & China & 548488 & $\mathrm{~V}$ & $243.3 \mathrm{~A}-\mathrm{C}$ \\
\hline Peking & Yes & China & 548402 & IV & $241.0 \mathrm{~A}-\mathrm{D}$ \\
\hline Wea & No & China & 548424 & II & $227.2 \mathrm{~A}-\mathrm{E}$ \\
\hline Gibson & No & United States & 548330 & IV & $224.9 \mathrm{~A}-\mathrm{E}$ \\
\hline Willomi & No & Japan & 548425 & III & 215.8 A-E \\
\hline Dunfield & Yes & China & 548318 & III & $215.8 \mathrm{~A}-\mathrm{E}$ \\
\hline Palmetto & Yes & China & 548480 & VII & 215.8 A-E \\
\hline Manchu & Yes & China & 548365 & III & $206.6 \mathrm{~B}-\mathrm{F}$ \\
\hline Tokyo & Yes & Japan & 548493 & VII & $202.0 \mathrm{~B}-\mathrm{G}$ \\
\hline Mukden & Yes & China & 548391 & II & 197.4 B-G \\
\hline Hartwig & No & United States & 543795 & $\mathrm{~V}$ & $188.3 \mathrm{C}-\mathrm{G}$ \\
\hline Williams 82 & No & United States & 518671 & III & $186.0 \mathrm{C}-\mathrm{G}$ \\
\hline Waseda & No & Japan & 548423 & II & $183.7 \mathrm{D}-\mathrm{G}$ \\
\hline Mandarin A & No & Canada & 438363 & I & $179.9 \mathrm{E}-\mathrm{G}$ \\
\hline Richland & Yes & China & 548406 & II & $179.9 \mathrm{E}-\mathrm{G}$ \\
\hline Roanoke & Yes & China & 548485 & VII & $172.2 \mathrm{E}-\mathrm{G}$ \\
\hline CNS & Yes & China & 548445 & VII & $169.9 \mathrm{E}-\mathrm{H}$ \\
\hline Bavendar Sp. A & No & United States & 548304 & III & $154.1 \mathrm{~F}-\mathrm{I}$ \\
\hline Mandarin & Yes & China & 548378 & I & $148.7 \mathrm{~F}-\mathrm{I}$ \\
\hline Mandarin (Ottawa) & Yes & China & 548379 & 0 & $147.0 \mathrm{G}-\mathrm{I}$ \\
\hline Manchuria & No & China & 548375 & I & $112.6 \mathrm{H}-\mathrm{J}$ \\
\hline Boone & No & China & 548309 & IV & $109.9 \mathrm{I}-\mathrm{J}$ \\
\hline Mandarin Yowa & No & France & 189890 & I & $80.3 \mathrm{~J}$ \\
\hline Early White Eyebrow & No & China & 548320 & 0 & $76.8 \mathrm{~J}$ \\
\hline Mandarin 507 & No & China & 548380 & I & $62.8 \mathrm{~J}$ \\
\hline
\end{tabular}

${ }^{y}$ Reported as ancestral to modern day public soybean cultivars released between 1947 to 1988 (10).

${ }^{\mathrm{z}}$ Means not connected by the same letter are significantly $(P=0.05)$ different by least significant difference. 
for resistance to $C$. truncatum. The method to inoculate soybean plants may be adapted to anthracnose on other crops or to other foliar diseases on soybean. The homemade moist incubation chambers alleviated the need for commercialized dew chambers. The

Table 6. Area under disease progress curve (AUDPC) for selected public soybean cultivars inoculated with Colletotrichum truncatum with their plant introduction (PI) number, maturity group (MG), and year of release

\begin{tabular}{|c|c|c|c|c|}
\hline Cultivar & PI & MG & $\begin{array}{l}\text { Year of } \\
\text { release }\end{array}$ & AUDPC $^{\mathbf{x}}$ \\
\hline Dwight & 597386 & II & 1997 & $304.1 \mathrm{~A}$ \\
\hline Hack & 548569 & II & 1984 & $284.7 \mathrm{AB}$ \\
\hline Hamilton & 540555 & IV & 1989 & $276.3 \mathrm{~A}-\mathrm{C}$ \\
\hline Williams 82 & 518671 & III & 1983 & $263.7 \mathrm{~A}-\mathrm{D}$ \\
\hline Omaha & 597382 & IV & 1996 & $263.1 \mathrm{~A}-\mathrm{D}$ \\
\hline LD00-3309 & 639740 & IV & 2006 & $251.3 \mathrm{~A}-\mathrm{D}$ \\
\hline Savoy & 597381 & II & 1996 & $240.8 \mathrm{~A}-\mathrm{E}$ \\
\hline Cisne & 593256 & IV & 1995 & $231.0 \mathrm{~A}-\mathrm{F}$ \\
\hline Jack & 540556 & II & 1989 & $230.7 \mathrm{~A}-\mathrm{F}$ \\
\hline Maverick & 598124 & III & 1996 & $229.5 \mathrm{~A}-\mathrm{F}$ \\
\hline Bell & 540554 & I & 1989 & $226.1 \mathrm{~A}-\mathrm{F}$ \\
\hline LD00-2817P & 658519 & IV & 2010 & $222.6 \mathrm{~A}-\mathrm{F}$ \\
\hline Saline & 578057 & III & 1993 & 213.0 A-G \\
\hline Ina & 606749 & IV & 1998 & $211.2 \mathrm{~B}-\mathrm{G}$ \\
\hline Chamberlain & 548635 & III & 1986 & $205.5 \mathrm{~B}-\mathrm{H}$ \\
\hline Pana & 597387 & III & 1997 & $204.9 \mathrm{~B}-\mathrm{H}$ \\
\hline Burlison & 533655 & II & 1988 & $199.7 \mathrm{~B}-\mathrm{H}$ \\
\hline Loda & 614088 & II & 2000 & $197.5 \mathrm{~B}-\mathrm{H}$ \\
\hline Rend & 606748 & IV & 1998 & 193.0 B-I \\
\hline Yale & 584441 & III & 1994 & $189.0 \mathrm{C}-\mathrm{I}$ \\
\hline Piatt & 574534 & III & 1993 & $178.1 \mathrm{D}-\mathrm{I}$ \\
\hline LN92-7369 & 607385 & II & 1999 & $154.5 \mathrm{E}-\mathrm{I}$ \\
\hline LN97-15076 & 633983 & IV & 2003 & $153.1 \mathrm{~F}-\mathrm{I}$ \\
\hline Macon & 593258 & III & 1995 & $142.2 \mathrm{~F}-\mathrm{I}$ \\
\hline Iroquois & 593259 & III & 1995 & $124.2 \mathrm{G}-\mathrm{J}$ \\
\hline Mandarin ${ }^{y}$ & 548378 & I & 1920 & $116.2 \mathrm{H}-\mathrm{J}$ \\
\hline Spry & 553051 & IV & 1991 & $104.6 \mathrm{I}-\mathrm{J}$ \\
\hline Mandarin $507^{z}$ & 548380 & I & 1943 & $49.3 \mathrm{~J}$ \\
\hline
\end{tabular}

${ }^{x}$ Means not connected by the same letter are significantly $(P=0.05)$ different by least significant difference.

y PI 548378 origin is China; historical origin is the United States, United States Department of Agriculture Arlington Farm, Arlington, VA; selected from PI 36653 from Sui Hua, Heilongjiang, China, in 1913; and released in 1920 (26).

${ }^{z}$ PI 548380 origin is China; historical origin is the United States, Wisconsin AES, Wisconsin, 507; selected from Mandarin; and released in 1943 (26). soybean genotypes that exhibited lower AUDPC values did not have an immune reaction to the pathogen; instead, the reaction was quantitative. Additional research will be needed to determine the inheritance of this type of resistance and to determine the nature of the resistance mechanisms producing this quantitative resistance.

In this study, a mycelial suspension for inoculation was used to test soybean for resistance to anthracnose. Results showed that this technique provided several advantages over conidial suspensions. The mycelial suspensions were highly infectious and easy to prepare in large quantities in liquid cultures. The preparation time for mycelial suspension was less than that for conidial suspension and could be used to compare isolates that produce no or few conidia in culture plates (unpublished). Other studies have also shown benefits of using mycelial fragments, including for Mycosphaerella fijiensis infection of banana plants (7).

Incubation period and humidity are important components for many foliar pathogens, including Colletotrichum spp. $(12,13,20)$. We found that longer incubation periods after inoculation increased the severity of anthracnose. Results were similar to those of a previous study, which showed that a longer period of wetness caused more severe anthracnose symptoms on inoculated soybean plants (20). Although it was not part of this study, it is presumed that the increased duration of moisture benefitted the fungus either directly, by allowing a longer period of optimal conditions for fungal growth, or indirectly, by increasing the susceptibility of plants to the pathogen with the increase of succulence of plant tissues (2).

Our results corroborated a previous study (20) that showed that younger plants were more susceptible to infection by $C$. truncatum. Soybean genotypes that had extreme differences in AUDPC values at the vegetative growth stage had similar differences at the reproductive growth stage. This indicates that the seedling stage may be

Table 7. Area under disease progress curve (AUDPC) for soybean genotypes Mandarin 507 and Williams 82 inoculated with Colletotrichum truncatum at two different growth stages

\begin{tabular}{lcc}
\hline Soybean genotype & Growth stage $^{\mathbf{y}}$ & AUDPC $^{\mathbf{z}}$ \\
\hline Williams 82 & V2-V3 & $12.4 \mathrm{~A}$ \\
Mandarin 507 & V2-V3 & $7.2 \mathrm{~B}$ \\
Williams 82 & R4-R6 & $4.9 \mathrm{C}$ \\
Mandarin 507 & R4-R6 & $1.7 \mathrm{D}$ \\
\hline
\end{tabular}

y $\mathrm{V}=$ vegetative growth stages and $\mathrm{R}=$ reproductive growth stages (8).

${ }^{\mathrm{z}}$ Means not connected by the same letter are significantly $(P=0.05)$ different by least significant difference.
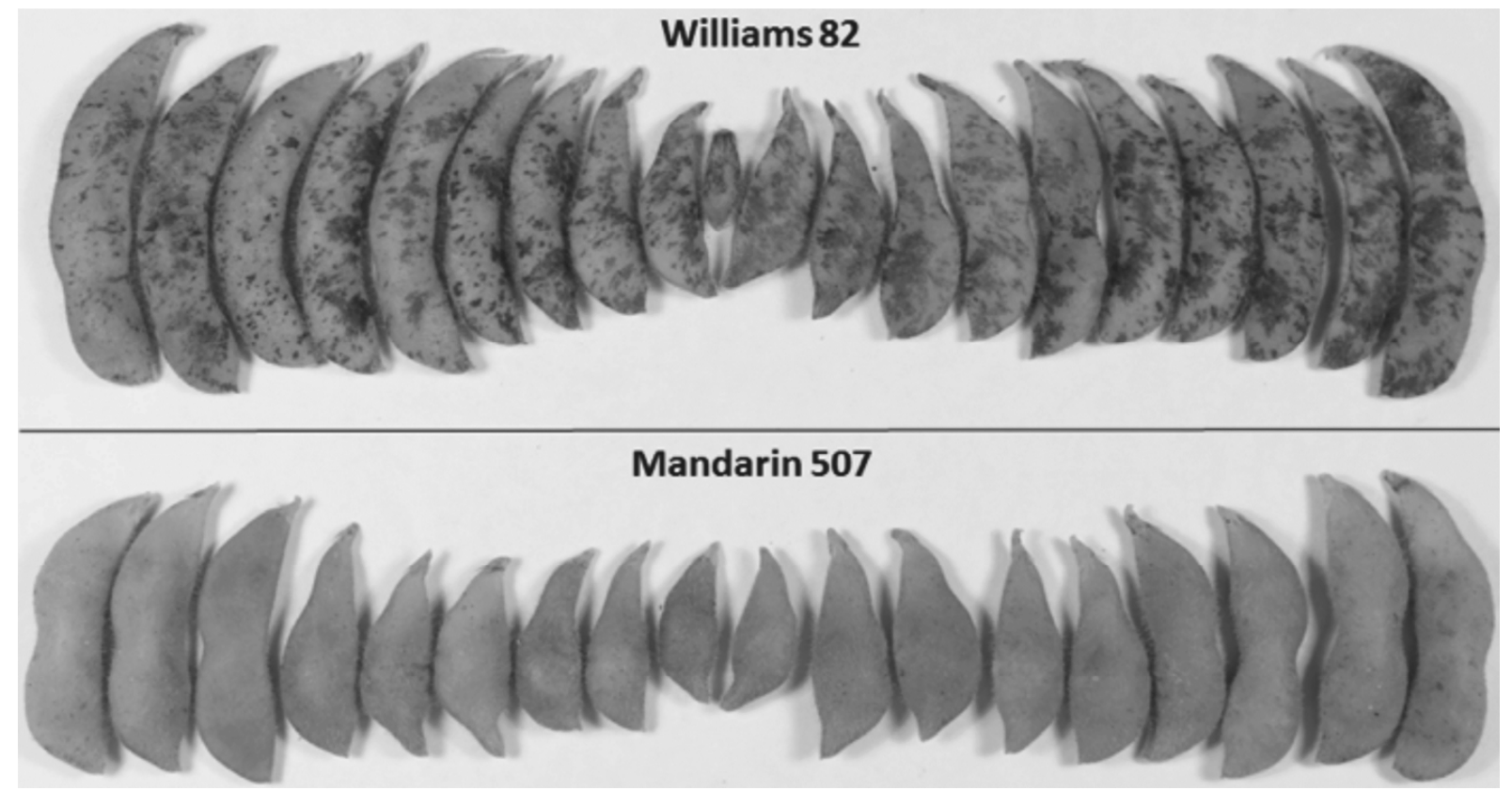

Fig. 1. Anthracnose on pods removed from plants of soybean genotypes Williams 82 and Mandarin 507 that were inoculated 20 days previously with Colletotrichum truncatum. 
an acceptable time to evaluate soybean genotypes for resistance to C. truncatum. Using seedlings allows the researcher to maximize space and time when evaluating many genotypes or populations to determine the inheritance of resistance.

The resistance in soybean to anthracnose discovered in our study was not complete because even the genotypes with the lowest severity ratings had some leaf and petiole necrosis. One of the most resistant genotypes in a previous study was Mandarin (18). We tested an additional four PI accessions with the name Mandarin from the soybean germplasm collection (26). Of these five, Mandarin 507 was also in the most resistant group and showed good consistency in all of the experiments. This cultivar, as well as Mandarin (Ottawa), was derived and selected from Mandarin (26), which originated from China. However, Mandarin, Mandarin (Ottawa), and Mandarin Yowa (from France) performed differently, suggesting that they are different genotypes.

Among the 14 ancestral lines examined in the present study, 8 were tested by Manandhar et al. (18), including A. K. Harrow, 'Dunfield', 'Manchu', Mandarin, Mandarin (Ottawa), 'Mukden', 'Peking', and 'Richland'. All had ratings similar to Williams 82, with the exception of Mandarin and Mandarin (Ottawa). Mandarin and Mandarin (Ottawa) contributed less than 1 and 12\%, respectively, of genes for the North American cultivars released from 1947 to 1988 (10).

Of the public soybean cultivars screened, only Iroquois and Spry had a level of resistance comparable with Mandarin 507. Both Iroquois and Spry have 'Harosoy' in their background (26), which has Mandarin (Ottawa) as one of its parents. In addition to showing a good level of foliar, petiole, and stem resistance, Mandarin 507 had few pod symptoms. Mandarin 507 and, possibly, Iroquois and Spry may be useful in further studies on inheritance and understanding the mechanisms of resistance which, to date, remain unknown. Further research needs to determine whether soybean resistance in the aboveground green tissues relates to resistance in seed and roots, and if the resistance is effective to multiple species of Colletotrichum that cause anthracnose.

\section{Acknowledgments}

We thank Dr. C. R. Bowen for field sampling and editorial review, and T. Herman for editorial review.

\section{Literature Cited}

1. Agrios, G. N. 2005. Diseases caused by Ascomycetes and Deuteromycetes (mitosporic fungi). Pages 483-500 in: Plant Pathology, fifth ed. Elsevier Academic Press, Boston.

2. Agrios, G. N. 2005. Effect of moisture. Pages 253-257 in: Plant Pathology, fifth ed. Elsevier Academic Press, Boston.

3. Backman, P. A., Williams, J. C., and Crawford, M. A. 1982. Yield losses in soybeans from anthracnose caused by Colletotrichum truncatum. Plant Dis. 66:1032-1034

4. Chen, L. S., Chu, C., Liu, C. D., Chen, R. S., and Tsay, J. G. 2006. PCRbased detection and differentiation of anthracnose pathogens, Colletotrichum gloeosporioides and C. truncatum, from vegetable soybean in Taiwan. J. Phytopathol. 154:654-662.

5. da Costa, I. F. D., Balardin, R. S., Medeiros, L. A. M., Lenz, G., Gulart, C. A., Zemolin, C. R., and Silva, T. M. B. 2009. Reaction of commercial germplasm of soybean to Colletotrichum truncatum. Trop. Plant Pathol. 34:47-50.

6. Delannay, X., Rodgers, D. M., and Palmer, R. G. 1983. Relative genetic contributions among ancestral lines to North American soybean cultivars. Crop Sci. 23:944-949.
7. Donzelli, B. G. G., and Churchill, A. C. L. 2007. A quantitative assay using mycelial fragments to assess virulence of Mycosphaerella fijiensis. Phytopathology 97:916-929.

8. Fehr, W. R., Caviness, C. E., Burmood, D. T., and Pennington, J. S. 1971 Stage of development descriptions for soybeans, Glycine max (L.) Merrill. Crop Sci. 11:929-931.

9. Gizlice, Z., Carter, T. E., and Burton, J. W. 1993. Genetic diversity in North American soybean: I. Multivariate analysis of founding stock and relation to coefficient of parentage. Crop Sci. 33:614-620.

10. Gizlice, Z., Carter, T. E., and Burton, J. W. 1994. Genetic base for North American public soybean cultivars released between 1947 and 1988. Crop Sci. 34:1143-1151.

11. Hartman, G. L., Manandhar, J. B., and Sinclair, J. B. 1986. Incidence of Colletotrichum spp. on soybeans and weeds in Illinois and pathogenicity of Colletotrichum truncatum. Plant Dis. 70:780-782.

12. Hong, J. K., and Hwang, B. K. 1998. Influence of inoculum density, wetness duration, plant age, inoculation method, and cultivar resistance on infection of pepper plants by Colletotrichum coccodes. Plant Dis. 82:10791083 .

13. Huber, L., and Gillespie, T. J. 1992. Modeling leaf wetness in relation to plant disease epidemiology. Annu. Rev. Phytopathol. 30:553-577.

14. Khan, M., and Sinclair, J. B. 1992. Pathogenicity of sclerotia- and nonsclerotia-forming isolates of Colletotrichum truncatum on soybean plants and roots. Phytopathology 82:314-319.

15. Little, T. M., and Hills, F. J. 1978. Agricultural Experimentation: Design and Analysis. John Wiley and Sons, New York.

16. Manandhar, J. B., and Hartman, G. L. 1999. Anthracnose. Pages 13-14 in: Compendium of Soybean Diseases. G. L. Hartman, J. B. Sinclair, and J. C. Rupe, eds. American Phytopathological Society, St. Paul, MN.

17. Manandhar, J. B., Hartman, G. L., and Sinclair, B. 1986. Colletotrichum destructivum, the anamorph of Glomerella glycines. Phytopathology 76:282-285.

18. Manandhar, J. B., Hartman, G. L., and Sinclair, J. B. 1986. Reaction of soybean germplasm maturity groups 000 to IV to anthracnose, 1984-1985. Biol. Cult. Tests Control Plant Dis. 1:32.

19. Manandhar, J. B., Hartman, G. L., and Sinclair, J. B. 1986. Reaction of soybean germplasm maturity groups V to X to anthracnose, 1984-1985. Biol. Cult. Tests Control Plant Dis. 1:33

20. Manandhar, J. B., Hartman, G. L., and Sinclair, J. B. 1988. Soybean germ plasm evaluation for resistance to Colletotrichum truncatum. Plant Dis. 72:56-59.

21. Manandhar, J. B., Kunwar, I. K., Singh, T., Hartman, G. L., and Sinclair, J. B. 1985. Penetration and infection of soybean leaf tissues by Colletotrichum truncatum and Glomerella glycines. Phytopathology 75:704-708.

22. Mueller, D. S., Nelson, R. L., Hartman, G. L., and Pedersen, W. L. 2003 Response of commercially developed cultivars and ancestral soybean lines to Fusarium solani f. sp. glycines. Plant Dis. 87:827-831.

23. Roy, K. W. 1982. Seedling diseases caused in soybean by species of Colle totrichum and Glomerella. Phytopathology 72:1093-1096.

24. Schneider, R. W., Dhingra, O. D., Nicholson, J. F., and Sinclair, J. B. 1974 Colletotrichum truncatum borne within the seedcoat of soybean. Phytopathology 64:154-155.

25. Shaner, G., and Finney, R. E. 1977. The effect of nitrogen fertilization on the expression of slow-mildewing resistance in Knox wheat. Phytopathology 67:1051-1056.

26. USDA-ARS. 2013. National Genetic Resources Program. Germplasm Resources Information Network (GRIN). National Germplasm Resources Laboratory, Beltsville, MD. http://www.ars-grin.gov/npgs/index.html

27. Wang, Y., Hobbs, H. A., Hill, C. B., Domier, L. L., Hartman, G. L., and Nelson, R. L. 2005. Evaluation of ancestral lines of US soybean cultivars for resistance to four soybean viruses. Crop Sci. 45:639-644.

28. Wrather, J. A., and Koenning, S. R. 2006. Estimates of disease effects on soybean yields in the United States 2003 to 2005. J. Nematol. 38:173-180.

29. Wrather, J. A., Stienstra, W. C., and Koenning, S. R. 2001. Soybean disease loss estimates for the United States from 1996 to 1998. Can. J. Plant Pathol. 23:122-131

30. Yang, H.-C., Haudenshield, J. S., and Hartman, G. L. 2014. Colletotrichum incanum sp. nov., a curved-conidial species causing soybean anthracnose in the USA. Mycologia 106:32-42. 